\title{
A convocação da assemabléia geral por acionistas
}

\section{Waldemar Ferreira}

1. No propósito de garantir os direitos da sociedade anônima em face de sua diretoria e, tambem, os da minoria dos acionistas, têm as leis disciplinadoras da sociedade de tal natureza estabelecido as condições mediante as quais a estes é lícito convocar a assembléia geral extraordinária. Pela regra do art. 89 do decreto-lei n. 2.627, de 26 de setembro de 1940, compete à diretoria convocar a assembléia geral, nos casos previstos em lei ou nos estatutos. Conferiu aquele artigo, porém, e bem avisadamente, direito idêntico:

a) ao consêlho fiscal, se a diretoria retardar por mais de um mês a da assembléia geral ordinária, e a extraordinária sempre que ocorrerem motivos graves e urgentes;

b) ao acionista, quando a diretoria retardar, por mais de dois mêses, a convocação, nos casos previstos em lei ou nos estatutos, ou quando, representando mais do quinto do capital social, aquele órgão não atender, no prazo de oito dias, a contar da data do requerimento, devidamente fundamentado, ao pedido de convocação.

2. Focalizou o texto, quanto à iniciativa dos acionistas, dois casos distintos. Vale bem examiná-los destacadamente, afim de tirarem-se as conclusões a cada qual pertinentes, de molde a evitar dúvidas originárias da apressada leitura do dispositivo legal, quando não de interpretação cerebrina e tendente a obstruir o direito dos acionistas, tão categoricamente outorgado por ele. 
3. Haverá anualmente, qual preceitúa o art. 98 do decreto-lei n. 2.627, a assembléia geral, que tomará as contas da diretoria, examinará e discutirá o balanço e o parecer do conselho fiscal, sobre eles deliberando. Essa é a assembléia geral ordinária. Realizar-se-á, imperativamente o determina o parágrafo único daquele artigo, "nos quatro primeiros mêses após à terminação do exercício social". E deverá, como já se viu, ser convocada pela diretoria.

4. Se, porém, a diretoria se mantiver inativa, deixando de fazer a convocação dentro daquele prazo, tenha, ou não, praticado as providências preliminares, enumeradas, no art. 99, e um mês se escôe, sem que a assembléia geral ordinária se realize, incumbe aos membros do consêlho fiscal, pelo disposto no art. 127, n. V, convocá-la. Tendo eles mandato ânuo, devem ter a cautela de não deixar a sociedade sem o seu órgão de fiscalização. Não sejam, portanto, omissos no cumprimento desse dever, em termos tão explicitos impostos por lei.

5. Têm os fiscais um mês para o cumprimento dessa obrigação. Decorrido outro, sem que a convocação se tenha feito, por a haver a diretoria retardado por mais de dois mêses, cabe ao acionista fazê-la. Ao acionista, a qualquer acionista, seja portador de uma apenas ou de centena de ações. Pouco importa o número de suas ações. Assiste-lhe, então, direito para reclamar à diretoria a convocação, por ela retardada, e de, não atendida sua reclamação, no prazo de oito dias, a contar da data do requerimento, fazê-la ele próprio. Isso, porém, quanto à assembléia geral ordinária.

6. Confere, ademais, o preceito em apreço ao acionista, e eis o outro caso, direito para, representando mais do quinto do capital social, convocar a assembléia geral extraordinária, quando a diretoria não atender, no prazo de 
oito dias, a contar da data do requerimento, devidamente fundamentado, ao pedido de convocação.

Teceram-se, em volume sobre o assunto, considerações a respeito do texto em apreço, a seguir reproduzidas.

7. “Compete à diretoria a convocação, como é de ver. órgão de administração, dirigindo e orientando os negócios sociais; conhecendo-os no seu conjunto e nos seus pormenores, está ela ao par de quanto se passa, quer quanto a eles, quer quanto ao exercício dos direitos dos acionistas, coletiva ou individualmente, pelo contacto direto em que com eles se encontra. Ainda quando o acionista, representando mais do quinto do capital social, pretenda fazer a convocação da assembléia geral extraordinariamente, como lho permite o art. $89, b)$, do decreto-lei n. 2.627, de 26 de setembro de 1940, à diretoria tem de dirigir-se, requerendo-lhe, em petição, devidamente fundamentada, que a convoque. Dentro de oito dias, deve ela convocá-la, sob pena de, findo aquele prazo, assistir ao acionista direito para isso. Não cabe à diretoria, portanto, entrar no exame do pedido, mas verificar se os seus sinatários são acionistas e representam mais do quinto do capital social. Entendeu-se de modo diverso, no regime do decr. n. 434 , de 4 de julho de 1891. Dava o art. 137 deste competência à administração para convocar a assembléia geral extraordinariamente, quando o requerimento lhe fosse dirigido por acionistas em número não menor de sete, e representando, pelo menos, o quinto do capital social. O pedido de convocação, todavia, carecia ser fundamentado com motivo, que não tivesse referência a matéria, atos e contas já apreciados e julgados em assembléia geral. Na competência dos administradores, portanto, residia a de verificar a legitimidade do pedido, com a faculdade de atendê-lo ou de indeferí-lo (1). Não existem, agora, condições daquele naipe, a subordinar o pedido. Basta re-

(1) Waldemar Fernerra, Questões de Direito Comercial, primeira série, de 1929, n. LIII, pag. 263. 
presente o acionista, ou quantos subscreverem o pedido, mais do quinto do capital social. A omissão da diretoria abre ensejo para a convocação pelo próprio acionista, findo o prazo de oito dias, ou quando ela retarde, por mais de dois mêses, a que estava na obrigação de fazer, pelos estatutos ou pela lei" (2).

8. Eis, pois, assentado o sentido do novo dispositivo legal. Não permite ele a interpretação de que, nos dois casos, a convocação da assembléia geral, tanto a ordinária retardada, quando a extraordinária pelos acionistas desejada, carece ser feita apenas, mais do que isso, necessariamente, por "um" acionista, exclusivamente, e acionista que represente, só ele, mais do quinto do capital social.

No regime do decr. 434 , de 4 de julbo de 1891, mercê do expresso em seu art. 137, n. 1, tinham os administradores competência para convocar extraordinariamente a assembléia geral, a requerimento de quaisquer acionistas, quando lhe fosse aquele "dirigido por sócios em número não menor de sete, e representando, pelo menos, um quinto do capital social". Foram, porém, aquele artigo e o subsequente substituidos, pelo decr. n. 23.324, de 6 de novembro de 1933, que firmou a nórma de independer "de número de acionistas requerentes a convocação da assembléia geral extraordinária a que se refere o decr. n. 434, de 4 de julho de 1891, uma urna vez que os sinatários da respetiva petição representem,

(2) Waldemar Ferreira, Compêndio de Sociedades Mercantis, segunda edição, revista e aumentada, de 1942, vol. 2, Sociedades Anônimas, $\S 30$, pag. 264 , e mais, ainda, $\S 43$, n. 2 , pag. 381 . Neste tópico, depois da alusão ao decr. n. 434, insistiu-se na doutrina firmada acima:

“Absteve-se o decreto-lei n. 2.627, de 26 de setembro de 1940, de entrar em considerações dessa natureza. Deixou-as em branco. São, não obstante, os administradores, que constituem a diretoria, os verificadores da legitimidade do pedido, podendo, portanto, deferi-lo ou indeferí-lo. Indeferindo-o, fica o acionista com a faculdade de promover a convocação da assembléia geral extraordinária. Conhecerá ela, então, da legitimidade da convocação, sem prejuizo do direito dos dissidentes de pleitear a anulação judicial de suas deliberações". 
pelo menos, metade do capital social". Justificou-se aquele decreto, em seu introito, entre outras, com a consideração de que o Congresso Internacional das Sociedades por Ações, reunido em Paris, em 1900, votou conclusão no sentido de que "a convocação de uma assembléia geral póde ser exigida por acionistas que possúam um certo número de ações que representem uma parte notavel do capital social, não obstante qualquer estipulação contrária dos estatutos".

Não se divorciou o decreto-lei n. 2.627, de 26 de setembro de 1940, daquela corrente doutrinária, ao aludir, no art. 89 , § único, $b$ ), ao acionista, afim de restringir o número e, dessarte, dificultar sobremaneira o que teve ele por intuito evidente facilitar. Referiu-se ele, genericamente, como é óbvio, ao acionista, para abstrair de qualquer número. $\mathrm{O}$ pedido de convocação tanto póde ser feito por um, como por cincoenta: o indispensavel é a representação de mais de um quinto do capital social. Representação, diz a lei. Não exige ela que o acionista possúa ou seja proprietário de ações que, somadas, dêm aquele montante. Quer isso dizer, portanto, que a convocação pọde ser pedida por um ou mais acionistas, contanto que todos eles possuam ou sejam titulares de ações que valham mais do que o quinto do capital, nada impedindo que o sinatário seja procurador dos demais e, por isso, represente mais de um quinto do capital social.

Seria interpretação diversa, sobre absurda, puramente cerebrina, refugindo dos principios doutrinários, que regem e orientam a matéria, de tanta relevância.

9. Raridade sempre foi que diretorias de sociedades anônimas deferissem pedidos de convocação de assembléias gerais, formulados por acionistas, ainda mesmo quando rigorosamente observados os requisitos legais. Sempre havia razão por que elas os denegassem, ainda os mais capciosos e abstrusos. Porque sempre assim foi e, provavelmente, não deixará de ser, pois revela, na generalidade dos casos, senão dissidio, discordância dos acionistas com elas, no 
projeto de código das sociedades, que a Câmara dos Deputados aprovou, em segunda discussão, em 1936, consignou-se dispositivo assecuratório do direito dos acionistas, nestes termos:

“Art. 176 - A convocação da assembléia geral extraordinária, quando provocada por acionistas, deve ser precedida de requerimento à diretoria, assinado por acionistas representando um décimo do capital social.

"Parágrafo único - Indeferido o pedido, assiste aos acionistas, bem assim se não fôr ele despachado dentro em quinze dias, a faculdade de requerer judicialmente a convocação, observando-se o disposto nos $\S \S 2$ e 3 do artigo anterior".

E os parágrafos assim se exprimiam:

“§ $20^{\circ}$ - Se o acionista não fôr atendido, tem direito de fazer ele próprio a convocação, declarando esta circunstância no convite, publicado pela imprensa local.

" $\$ 3 .^{\circ}$ - Se a diretoria dificultar ou impedir, por qualquer fórma $\epsilon$ sob qualquer pretesto, a reunião, deixando de apresentar os livros necessários para o seu funcionamento, os acionistas podem requerer ao juiz de direito da comarca a convocação da assembléia, que se reunirá na sala das audiências, sob sua presidência, servindo o escrivão de secretário, observadas as disposições estatutárias" (3).

Como, então se advertiu, "a diretoria tem meios para tornar impossivel a realização da assembléia convocada por acionistas, o que a prática tem demonstrado", procurou-se, nesse e em outros casos, a intervenção judicial, afim de evitar a dualidade de assembléias e diretorias, que tanto contribuem para a desorganização da vida administrativa da sociedade anônima.

Não seguiu o decreto-lei vigente essa orientação, mas retirou da diretoria o exame da conveniência ou inconveniência da convocação da assembléia geral dos acionistas,

(3) Waldemar Ferreira, Código das Sociedades Comerciais, edição de 1938, pags. 40, n. 34, e 132. 
por um ou alguns deles pedida. Cabe-lhe, tão somente, verificar se os sinatários do pedido são, ou não, acionistas e se representam mais de um quinto do capital social.

10. O pedido deve ser devidamente fundamentado, refere o texto; mas isso não para que a diretoria entre no exame da fundamentação, senão apenas para que ela possa, na convocação, indicar a órdem do dia da assembléia geral. "Os convites ou anuncios mencionarão, ainda que sumariamente, a órdem do dia da assembléia e o local, o dia e a hora da reunião". Dispõe isso o art. 88 do decreto-lei $\mathbf{n}$. 2.627, de 26 de setembro de 1940, ao estabelecer a fórma da convocação da assembléia geral. Cuidando-se, simplesmente, de reformar os estatutos, quando a lei, para o caso, não exija relatório da diretoria e parecer do consêlho fiscal, a justificação do pedido tem que ser sumária muitas vezes, nada impedindo, entretanto, seja circunstanciada e explicita. Basta que se considere a hipotese de ter a proposta de refórma estatutária por objetivo a redução do cargo de diretores, como meio de afastar os que se tenham mostrado inconvenientes aos interesses sociais, sem que, todavia, queiram os acionistas tornar público o fundamento dessa medida, que importará no desabôno público dos diretores visados, para que se possa admitir a convocação da assembléia geral para a refórma dos estatutos, nos termos da proposta que, instalada ela, lhe será submetida.

Tendo ela, pelo art. 87 do decreto-lei vigente, poderes para resolver todos os negócios relativos ao objeto da exploração da sociedade e para tomar as decisões que julgar convenientes à defêsa desta e ao desenvolvimento de suas operações, cabe-lhe, certamente, o de ratificar sua convocação, se praticada qualquer irregularidade não fundamental, e passar a deliberar validamente.

São Paulo, 20 de julho de 1942. 